\title{
Characteristics of febrile urinary tract infections in older male adults
}

\author{
Alex Smithson ${ }^{1 *} \mathbb{D}$, Javier Ramos², Esther Niño², Alex Culla², Ubaldo Pertierra², Michele Friscia² \\ and Maria Teresa Bastida ${ }^{3}$
}

\begin{abstract}
Background: Urinary tract infections (UTI) are among the most frequent bacterial infections in older adults. The aim of the study was to analyse the existence of differences in clinical features, microbiological data and risk of infection by multidrug-resistant organisms (MDRO) between older and non-older men with febrile UTI (FUTI).

Methods: This was an ambispective observational study involving older males with a FUTI attended in the Emergency Department. Variables collected included age, comorbidity, diagnostic of healthcare-associated (HCA)-FUTI, clinical manifestations, hospitalization, mortality, and microbiological data.

Results: Five hundred fifty-two males with a FUTI, 329 (59.6\%) of whom were older adults, were included. Older males had a higher frequency of HCA-FUTI $(p<0.001)$, increased Charlson scores $(p<0.001)$, had received previous antimicrobial treatment more frequently $(p<0.001)$ and had less lower urinary tract symptoms $(p<0.001)$. Older patients showed a lower frequency of FUTI caused by E. coli $(p<0.001)$ and a higher rate of those due to Enterobacter spp. $(p=0.003)$ and $P$. aeruginosa $(p=0.033)$. Resistance rates to cefuroxime $(p=0.038)$, gentamicin $(p=0.043)$, and fluoroquinolones $(p<0.001)$ in E. coli isolates and the prevalence of extended-spectrum beta-lactamase and AmpC producing E. coli and Klebsiella spp. strains $(p=0.041)$ and MDRO $(p<0.001)$ were increased in older males. Inadequate empirical antimicrobial treatment $(p=0.004)$, frequency of hospitalization $(p<0.001)$, and all cause in-hospital mortality $(p=0.007)$ were higher among older patients. In the multivariate analysis, being admitted from an long term care facility (OR 2.4; 95\% Cl: 1.06-5.9), having a urinary tract abnormality (OR 2.2; 95\% Cl: 1.2-3.8) and previous antimicrobial treatment (OR 3.2; 95\% Cl: 1.9-5.4) were associated to FUTI caused by MDRO.
\end{abstract}

Conclusions: Older male adults with a FUTI have different clinical characteristics, present specific microbiological features, and antimicrobial resistance rates. In the multivariate analysis being an older male was not associated with an increased risk of FUTI caused by MDRO.

Keywords: Older adults, Males, Febrile urinary tract infection

\section{Background}

The number of older adults is increasing in virtually every country and will continue to grow over the coming decades. According to the 2018 Ageing Report, by 2050 older adults will represent $28 \%$ of the European Union citizens with an old-age dependency ratio of $55 \%$ of the working-age population [1]. With an ageing and highly dependent society the burden of infectious diseases is expected to increase mainly due to a high prevalence of

\footnotetext{
* Correspondence: asa30412@hotmail.com

${ }^{1}$ Infectious Diseases Unit, Fundació Hospital de l'Esperit Sant, C/Avinguda

Mossen Pons i Rabadà s/n, 08923 Santa Coloma Gramenet, Spain

Full list of author information is available at the end of the article
}

older people with comorbid conditions, long-term institutionalization, frailty and a weakened immune system [2]. Infections in the older adults have specific characteristics that have to be recognised in order to provide an optimal care such as uncommon clinical presentations, high rates of organ failure and antimicrobial interactions together with an increased severity and risk of infections caused by multidrug-resistant organisms (MDRO) [2].

Urinary tract infections (UTI) are one of the most common bacterial infections affecting geriatric patients and the main source of community acquired bacteremia $[3,4]$. After pneumonia, UTI represent the second cause

(c) The Author(s). 2019 Open Access This article is distributed under the terms of the Creative Commons Attribution 4.0 International License (http://creativecommons.org/licenses/by/4.0/), which permits unrestricted use, distribution, and reproduction in any medium, provided you give appropriate credit to the original author(s) and the source, provide a link to the Creative Commons license, and indicate if changes were made. The Creative Commons Public Domain Dedication waiver (http://creativecommons.org/publicdomain/zero/1.0/) applies to the data made available in this article, unless otherwise stated. 
of hospital admission due to an infection in the older adults [5]. Despite their high frequency, UTI are frequently overdiagnosed due to the high prevalence of asymptomatic bacteriuria (ASB) in older populations which may lead to an incorrect diagnostic and unnecessary antimicrobial treatment in the presence of nonspecific urinary symptoms $[3,6]$. This increased exposure to antimicrobials is one of the main factors explaining the high prevalence of UTI due to MDRO in the older adults including those caused by extendedspectrum betalactamase (ESBL) producing Enterobacteriaceae $[7,8]$.

Women are more prone to experience UTI although rates tend to equalise in ageing males due to impaired normal voiding mainly associated with benign prostatic hyperplasia (BPH) [9]. The main consequence of these voiding difficulties is the generation of a retrograde turbulent urine flow, enabling the ascension of uropathogens to the bladder and eventually into the prostate, which explains the high frequency of prostatic involvement in males with UTI [10]. Therefore, most febrile UTI (FUTI) in males should be considered as acute bacterial prostatitis $(\mathrm{ABP})$ and treated using antimicrobials with an adequate prostatic diffusion such as fluoroquinolones (FQ) [11]. Increasing antimicrobial resistance rates hinder the eradication of the bacteria from the prostate thus becoming the source of recurrent UTI in males [3].

The majority of the studies that have analysed the characteristics of FUTI in older populations have focused on women $[12,13]$. Therefore, we believe there is a knowledge gap regarding the characteristics of FUTI in older males. The objective of this study was to investigate the existence of differences in clinical features, microbiological data and risk of infection by MDRO between older and non-older men with FUTI.

\section{Methods}

\section{Study design}

This was an ambispective observational study in which we evaluated males aged $\geq 18$ years with a FUTI and a positive urine culture seen at the emergency department (ED) of a 165-bed primary care hospital from 2008 to 2015. Information was recorded retrospectively until 2009 and prospectively thereafter. FUTI was defined as an axillary temperature $\geq 38^{\circ} \mathrm{C}$, measured at home or the ED, and one or more lower urinary tract symptoms (LUTS) including urinary urgency, frequency and/or dysuria. In the absence of LUTS the patient was diagnosed as having a FUTI when no additional focus of infection was identified. FUTI episodes with negative or polymicrobial urine cultures were excluded from the analysis. The study was approved by the Clinical Research Ethics Committee of the "La Fundació Unió Catalana d'Hospitals" (approval number: CEIC 16/
58). Written informed consent was obtained from patients prospectively included.

Study population, description of measures and definitions Patients were divided into older and non-older males. Male patients aged 65 years or above were identified as older patients. Males aged between 65 and 79 were considered early older patients while those aged 80 years or above were considered to be late older patients. Men under 65 were defined as non-older. The variables collected from each patient included age, dementia, healthcare-associated (HCA)-FUTI, diabetes mellitus, kidney failure, cirrhosis, neoplastic disease, chronic obstructive lung disease, heart failure, use of immunosuppressives in the previous 30 days, comorbidity Charlson age adjusted score [14], antibiotic treatment in the prior 30 days, existence of urinary tract abnormalities or past UTI episodes. We also recorded information regarding the patients symptoms and from their physical examination at the ED including the axillary temperature and the mean arterial pressure (MAP). Patients were tracked until hospital discharge or death. In case of recurrent FUTI, only the initial episode was analysed.

We considered that the patient had a HCA-FUTI in case of: hospitalization for 2 or more days in the previous 90 days; residence in an long-term care facility (LTCF); intravenous therapy at home or in a day hospital, hemodialysis, specialized nursing care, invasive urinary tract instrumentation, 30 days before the FUTI; presence of an indwelling urethral catheter (IUC) in place or removed $48 \mathrm{~h}$ before the infection including short term ( $<30$ days $)$ and long term $(\geq 30$ days $)$ catheters. Patients without any of the prior criteria were catalogued as having a community-acquired FUTI.

Urine specimens were collected from clean-catch midstream urine. In case of long-term IUC it was recommended to obtain urine samples from a newly inserted catheter. Samples were cultured on CLED and MacConkey agar and considered positive in case of bacterial growth $\geq$ $10^{3}$ colony-forming units $/ \mathrm{mL}$. Standard biochemical methods were used for microbiological identification. Antimicrobial susceptibility of the isolated bacteria was performed by the disk diffusion technique according to the recommendations of the Clinical and Laboratory Standards Institute. The antibiotics tested included: amoxicillin, amoxicillin-clavulanate acid, cefuroxime, ceftriaxone, imipenem, gentamicin, nalidixic acid, ciprofloxacin, cotrimoxazole, and fosfomycin. Resistant and intermediate strains were pooled together for statistical analysis. The isolates were screened for ESBLs and Amp-C $\beta$-lactamases production by phenotypic methods. Microorganisms were considered as MDRO in case of expressing an acquired resistance to at least one agent in three or more antimicrobial categories [15]. 
The 2001 definitions were used to define severe sepsis and septic shock [16]. Inadequate empirical antimicrobial treatment (IEAT) was defined in case the isolated uropathogen was resistant to the first antibiotic administered at the ED or when treating with a third-generation cephalosporin (TGC) in monotherapy FUTI due to microorganisms with inducible chromosomal betalactamases (mainly Enterobacter spp., Serratia spp., C. freundii, M. morgagnii and Providencia spp). All-cause in-hospital mortality was defined when the patient died during the hospitalization independently of its causes while FUTI-related in-hospital mortality when the patient died due to the infection.

\section{Statistical analysis}

Dichotomous variables are presented as number of patients (percentages) and continuous variables as mean $( \pm$ standard deviations). Dichotomous variables were compared by using the Chi-square or the Fisher exact test as appropriate while continuous variables were compared by the Student $t$-test or the Mann-Whitney U-test. A logistic regression analysis was performed to identify independent variables associated with infections caused by MDRO. Variables with a $p<0.1$ in the univariate analysis were included in the multivariate analysis. Model validity was evaluated by the Hosmer-Lemeshow test for estimating goodness of fit. Statistical significance was defined as a two-tailed $P$ value of $<0.05$. Data were analyzed with SPSS 20.0.

\section{Results}

Five hundred and fifty-two males with a FUTI attended in the ED were included in the study. Three hundred and twenty-nine (59.6\%) were older and 223 (40.4\%) non-older patients. Among the older males, 210 (63.8\%) were classified as early older and $119(36.2 \%)$ as late older patients. Overall, 356 patients $(64.5 \%)$ had one or more chronic medical conditions. Of the included patients, 239 (43.4\%) had a previous diagnosis of $\mathrm{BPH}$ which represented the most common urinary tract abnormality. The baseline characteristics, clinical features, empirical treatment and outcomes of the patients are shown in Table 1. Older males had an increased frequency of HCA-FUTI, and the vast majority of the medical conditions analysed and thus had higher Charlson scores. Previous UTI episodes, the existence of urinary tract abnormalities, and antimicrobial intake in the preceding month, mainly with $\mathrm{FQ}$, were also more common in older patients. In addition, older males more frequently had an IUC half of which were longterm catheters and the rest short-term catheters mainly placed after urological surgery. None of the patients were on hemodialysis.
Regarding the clinical presentation, older males presented less LUTS, flank pain and lumbar tenderness with a similar degree of fever than non-older males. The MAP was lower in the older patients although no differences in the frequency of severe sepsis and septic shock were found when compared to non-older patients. Besides, older males presented an increased frequency of bacteremic FUTI.

The isolated uropathogens and their antimicrobial resistant pattern is shown in Table 2. E. coli was the predominant pathogen in older and non-older patients followed by $K$. pneumonia and $P$. aeruginosa. E. coli was less commonly isolated in older males, although it was still the most common causal uropathogen. Resistance rates to cefuroxime, gentamicin, and FQ were higher in E. coli strains isolated from older patients. When evaluated together, ESBL and AmpC producing E. coli and Klebsiella spp. were more prevalent among older patients. No carbapenemase-producing Enterobacteriaceae strains were isolated during the study period. The frequency of Enterobacter spp. and P. aeruginosa was also higher in older males. Patients with long-term IUC had a lower frequency of FUTI caused by E. coli (35\% vs $74 \% ; p<0.001$ ), and an increased risk of those caused by $K$. pneumoniae (22.5\% vs $7.4 \% ; p$ 0.004), P. aeruginosa (17.5\% vs $3.5 \% ; p 0.001)$, and P. mirabilis (10\% vs $2.5 \%$; $p$ 0.028) together with higher rates of infections caused by MDRO (Table 3) when compared to patients with short-term IUC.

As shown in Table 3 the frequency of infections caused by MDRO was higher in older patients. In the multivariate analysis independent risk factors for having a FUTI caused by a MDRO were coming from an LTCF, having a urinary tract abnormality and recent antimicrobial treatment but not with being an older male patient.

Regarding empirical antimicrobial treatment, TGC was the main therapeutic option used in older and non-older patients. A higher number of older males received empirical treatment with either a carbapenem or with piperacillin-tazobactam (Table 1). Older patients more frequently received an IEAT and were treated with OPAT, mainly with ertapenem in $25(46.3 \%)$ cases and with ceftriaxone in $23(42.6 \%)$ patients. Older males also required hospital admission more often with longer length of hospitalization and exhibited an increased crude and attributable in-hospital mortality compared with non-older patients (Table 1). A multivariate analysis of risk factors associated to in-hospital mortality was not performed due to the small number of deaths among the included patients.

\section{Discussion}

According to our study, older males with a FUTI present specific clinical characteristics, different microbiological 
Table 1 Basal characteristic, clinical features, empirical antimicrobial treatment and outcomes of included patients and analysis of existing differences between older and non-older patients with a febrile urinary tract infection

\begin{tabular}{|c|c|c|c|c|}
\hline Characteristics $^{a}$ & All patients $(n=552)$ & Older $(n=329)$ & Non-older $(n=223)$ & $P$ value \\
\hline \multicolumn{5}{|l|}{ Baseline conditions } \\
\hline Age (years) & $66.1 \pm 16.7$ & $77.3 \pm 7.6$ & $49.5 \pm 12.2$ & $<0.001$ \\
\hline HCA-FUTI & $203(36.8)$ & $177(53.8)$ & $26(11.7) \mathrm{s}$ & $<0.001$ \\
\hline Previous hospital admission & $130(23.6)$ & $114(34.7)$ & $16(7.2)$ & $<0.001$ \\
\hline Long term care facility & $46(8.3)$ & $43(13.1)$ & $3(1.3)$ & $<0.001$ \\
\hline IV home-day hospital treatment & $13(2.4)$ & $9(2.7)$ & $4(1.8)$ & 0.47 \\
\hline Specialized nursing care & $7(1.3)$ & $6(1.8)$ & $1(0.4)$ & 0.25 \\
\hline Indwelling urinary catheter & $76(13.8)$ & $66(20.1)$ & $10(4.5)$ & $<0.001$ \\
\hline Long-term IUC & $40(7.2)$ & $33(10)$ & $7(3.1)$ & 0.002 \\
\hline Short- term IUC & $36(6.5)$ & $33(10)$ & $3(1.3)$ & $<0.001$ \\
\hline Invasive urinary intrumentation & $110(19.9)$ & $98(29.8)$ & $12(5.4)$ & $<0.001$ \\
\hline Dementia & $64(11.6)$ & $62(18.8)$ & $2(0.9)$ & $<0.001$ \\
\hline Diabetes mellitus & $148(26.8)$ & $113(34.3)$ & $35(15.7)$ & $<0.001$ \\
\hline Chronic kidney failure & $54(9.8)$ & $49(14.9)$ & $5(2.2)$ & $<0.001$ \\
\hline Cirrhosis & $9(1.6)$ & $5(1.5)$ & $4(1.8)$ & 1 \\
\hline Neoplasia & $81(14.7)$ & $72(21.9)$ & $9(4)$ & $<0.001$ \\
\hline Heart failure & $8(1.4)$ & $7(2.1)$ & $1(0.4)$ & 0.15 \\
\hline Chronic obstructive lung disease & $100(18.1)$ & $90(27.4)$ & $10(4.5)$ & $<0.01$ \\
\hline Immunosuppressive or corticosteroid treatment & $11(2)$ & $7(2.1)$ & $4(1.8)$ & 1 \\
\hline Charlson score & $3.6 \pm 2.5$ & $5.1 \pm 1.7$ & $1.3 \pm 1.6$ & $<0.001$ \\
\hline Previous UTI & $222(45.5)$ & $152(53.7)$ & $70(34.1)$ & $<0.001$ \\
\hline Urinary tract abnormality & $339(61.5)$ & $252(76.8)$ & $87(39)$ & $<0.001$ \\
\hline $\mathrm{BPH}$ & $239(43.4)$ & $187(57)$ & $52(23.3)$ & $<0.001$ \\
\hline Urogenital cancer & $48(8.8)$ & $44(13.6)$ & $4(1.8)$ & $<0.001$ \\
\hline Previous antibiotic treatment & $179(32.6)$ & $135(41.3)$ & $44(19.8)$ & $<0.001$ \\
\hline Aminopenicillins & $60(11)$ & $42(13)$ & $18(8.2)$ & 0.081 \\
\hline Fluoroquinolones & $54(9.9)$ & $41(12.7)$ & $13(5.9)$ & 0.010 \\
\hline TGC & $16(2.9)$ & $11(3.4)$ & $5(2.3)$ & 0.44 \\
\hline Fosfomycine & $10(1.8)$ & $9(2.8)$ & $1(0.5)$ & 0.055 \\
\hline \multicolumn{5}{|l|}{ Clinical presentation } \\
\hline LUTS & $359(65.3)$ & $172(52.4)$ & $187(84.2)$ & $<0.001$ \\
\hline Flank pain & 89 (16.2) & $31(9.5)$ & $58(26.1)$ & $<0.001$ \\
\hline \multicolumn{5}{|l|}{ Physical examination } \\
\hline Temperature & $37.7 \pm 1$ & $37.7 \pm 1.1$ & $37.7 \pm 0.9$ & 0.85 \\
\hline $\operatorname{MAP}(\mathrm{mmHg})$ & $93.4 \pm 15.3$ & $91.1 \pm 15.3$ & $96.9 \pm 14.7$ & $<0.001$ \\
\hline Lumbar tenderness & $94(22.1)$ & $40(17.3)$ & $54(27.7)$ & 0.010 \\
\hline Prostatic tenderness & $81(42.6)$ & $35(37.2)$ & $46(47.9)$ & 0.13 \\
\hline \multicolumn{5}{|l|}{ Laboratory } \\
\hline WBC count (leukocytes/mm³) & $13,903 \pm 5743$ & $13,348 \pm 5536$ & $14,759 \pm 5961$ & 0.006 \\
\hline Creatinine (mg/dl) & $1.2 \pm 0.7$ & $1.4 \pm 0.8$ & $1.1 \pm 0.4$ & $<0.010$ \\
\hline Bacteremia & $120(31.6)$ & $92(38)$ & $28(20.3)$ & $<0.010$ \\
\hline \multicolumn{5}{|l|}{ Treatment } \\
\hline Empirical treatment with TGC & $307(55.6)$ & $176(53.5)$ & $131(58.7)$ & 0.22 \\
\hline
\end{tabular}


Table 1 Basal characteristic, clinical features, empirical antimicrobial treatment and outcomes of included patients and analysis of existing differences between older and non-older patients with a febrile urinary tract infection (Continued)

\begin{tabular}{|c|c|c|c|c|}
\hline Characteristics $^{\mathrm{a}}$ & All patients $(n=552)$ & Older $(n=329)$ & Non-older $(n=223)$ & $P$ value \\
\hline Empirical treatment with carbapenems or PT & $59(10.7)$ & $46(14)$ & $13(5.8)$ & 0.002 \\
\hline IEAT & $95(17.2)$ & $69(21)$ & $26(11.7)$ & 0.004 \\
\hline OPAT & $71(12.9)$ & $54(16.4)$ & $17(7.6)$ & 0.002 \\
\hline \multicolumn{5}{|l|}{ Outcomes } \\
\hline Severe sepsis or septic shock & $17(3.1)$ & $12(3.6)$ & $5(2.2)$ & 0.35 \\
\hline Hospital admission & $266(48.2)$ & $197(59.9)$ & $69(30.9)$ & $<0.001$ \\
\hline Length of hospitalisation (days) & $2.6 \pm 4.1$ & $3.3 \pm 4.6$ & $1.4 \pm 2.9$ & $<0.001$ \\
\hline Length antimicrobial therapy (days) & $16.3 \pm 6.7$ & $16 \pm 7$ & $16.8 \pm 6.5$ & 0.19 \\
\hline All-cause in-hospital mortality & $15(2.7)$ & $14(4.3)$ & $1(0.4)$ & 0.007 \\
\hline Attributable in-hospital mortality & $8(1.4)$ & $8(2.4)$ & 0 & 0.024 \\
\hline
\end{tabular}

Abbreviations: BPH Benign prostatic hyperplasia, HCA-FUTI Healthcare-associated febrile urinary tract infection, IEAT Inadequate empirical antimicrobial treatment, IUC Indwelling urinary catheter, LUTS Lower urinary tract symptoms, MAP Mean arterial pressure, OPAT Outpatient parenteral antimicrobial therapy, PT Piperacillintazobactam, TGC Third-generation cephalosporins, UTI Urinary tract infections, WBC White blood cell

${ }^{a}$ Data presented as mean \pm standard deviation (SD) or numbers of patients (percentages)

and antimicrobial-resistant patterns and outcomes when compared to non-older males. Due to the high frequency of UTI among older patients it is important to consider these differences when attending geriatric males with FUTI in the ED in order to provide an optimal therapeutic care.

Normal voiding is the most important defense against UTI. Increased postvoid residual volume, which occurs in ageing males mainly related to $\mathrm{BPH}$, causes urinary stasis and predisposes to UTI. Urinary tract abnormalities and IUC are additional contributors to UTI in geriatric patients $[3,17,18]$. As expected, a higher frequency of urinary tract abnormalities, mainly BPH but also urogenital cancer, was observed in older patients. In a study by Søgaard et al., acute pyelonephritis in patients older than 50 years was identified as a marker of urogenital cancer suggesting that older patients with FUTI should be evaluated to rule out this possibility [19].

Regarding the clinical presentation, more than half of the included older males presented LUTS, in accordance to what has been previously described [3]. Despite the frequent existence of urinary symptoms in older males, we observed a lower frequency of LUTS, flank pain and lumbar tenderness compared to non-older patients. A lower frequency of localizing urinary symptoms in older patients with a FUTI has been observed in previous studies, particularly in those living in $\operatorname{LTCF}[3,12,20]$. Although fever is frequently absent or blunted in geriatric patients with an acute infection, no differences in the degree of fever were seen between older and non-older patients [21]. Fever without localizing genitourinary signs and symptoms is the most common presentation of symptomatic UTI in residents from an LTCF with an IUC [3]. As pyuria and bacteriuria are practically constant in patients with a long-term IUC when fever is present an alternative focus of infection has to be ruled out before being attributed to a urinary infection [18].

The evaluation of UTI in geriatric patients can be challenging due to defective communication, functional disability and the existence of chronic LUTS usually not attributable to UTI $[3,18]$. Although non-specific changes in the clinical status of older patients such as delirium, increased falls, fatigue or loss of appetite, are frequently attributed to UTI, particularly in the presence of a positive urine culture, the value of these symptoms as indicators of a proper UTI has been questioned [3, 6, 22, 23]. According to a recent decision tool for deciding empiric antimicrobial treatment in frail older adults with suspected UTI and the 2019 IDSA guidelines for the management of ASB, most non-specific symptoms in the absence of LUTS or other signs of infection should not be attributed to UTI $[24,25]$. Therefore, due to the high prevalence of pyuria and ASB in older patients, urinalysis should only be performed when signs and symptoms of UTI are present $[3,18,24]$.

In our study, FUTI in older males were less commonly caused by $E$. coli with an increased frequency of infections due to other gram-negative bacteria, which is in accordance with previous studies [2]. E. coli isolated from older males exhibited increased resistance rates to cefuroxime, gentamicin, and FQ. We also observed a higher prevalence of ESBL and AmpC producing E. coli and Klebsiella spp. strains with rates similar to the ones reported by Alvarez et al. among older patients with UTI [26]. The impact of age in the frequency of FUTI caused by MDRO has been observed in some studies $[8,12]$ but not in others $[27,28]$. Interestingly, men seem to have an increased risk of infection with ESBL-producing Enterobacteria and other MDRO compared to women [8, 28, 29].

In the multivariate analysis, coming from an LTCF, having a urinary tract abnormality and recent antimicrobial 
Table 2 Isolated uropathogens and antimicrobial resistance profiles

\begin{tabular}{|c|c|c|c|c|}
\hline Uropathogens $^{a}$ & All patients $(n=552)$ & Older $(n=329)$ & Non-Older $(n=223)$ & $P$ value \\
\hline Escherichia coli & $393(71.2)$ & $206(62.6)$ & 187(83.9) & $<0.001$ \\
\hline Amoxicillin & $254(69.2)$ & $137(71.4)$ & $117(67)$ & 0.35 \\
\hline Amoxicillin-clavulanate & $52(13.3)$ & $33(16.2)$ & $19(10.2)$ & 0.080 \\
\hline Cefuroxime sodium & $38(9.7)$ & $26(12.6)$ & $12(6.4)$ & 0.038 \\
\hline Ceftriaxone $^{\mathrm{b}}$ & $35(8.9)$ & $23(11.2)$ & $12(6.4)$ & 0.099 \\
\hline Gentamicin & $30(7.7)$ & $21(10.2)$ & $9(4.8)$ & 0.043 \\
\hline Fluoroquinolones & $153(38.9)$ & $100(48.5)$ & $53(28.3)$ & $<0.001$ \\
\hline Co-trimoxazol & $102(26.8)$ & $56(28.3)$ & $46(25.3)$ & 0.51 \\
\hline Fosfomycine & $8(2.1)$ & $6(3.1)$ & $2(1.1)$ & 0.28 \\
\hline Klebsiella spp. ${ }^{c}$ & $56(10.1)$ & $40(12.2)$ & $16(7.2)$ & 0.057 \\
\hline Amoxicilline-clavulanate & $13(23.2)$ & $8(20)$ & $5(31.3)$ & 0.48 \\
\hline Ceftriaxone $^{d}$ & $12(21.4)$ & $9(22.5)$ & $3(18.8)$ & 1 \\
\hline Fluoroquinolones & $15(26.8)$ & $12(30)$ & $3(18.8)$ & 0.51 \\
\hline Co-trimoxazol & $11(20.8)$ & $8(21.1)$ & $3(20)$ & 1 \\
\hline ESBL and AmpC producing E. coli and Klebsiella spp. & $48(10.7)$ & $33(13.4)$ & $15(7.4)$ & 0.041 \\
\hline Enterobacter spp. ${ }^{e}$ & $21(3.8)$ & $19(5.8)$ & $2(0.9)$ & 0.003 \\
\hline Serratia spp. & $4(0.7)$ & $3(0.9)$ & $1(0.4)$ & 0.65 \\
\hline Citrobacter spp. & $4(0.7)$ & $1(0.3)$ & $3(1.3)$ & 0.3 \\
\hline Morganella spp. & $5(0.9)$ & $4(1.2)$ & $1(0.4)$ & 0.65 \\
\hline Proteus mirabilis & $17(3.1)$ & $14(4.3)$ & $3(1.3)$ & 0.052 \\
\hline Pseudomona aeruginosa & $25(4.5)$ & $20(6.1)$ & $5(2.2)$ & 0.033 \\
\hline Fluoroquinolones & $7(28)$ & $7(35)$ & 0 & 0.27 \\
\hline Other Gram negative bacteria ${ }^{f}$ & $2(0.4)$ & $2(0.6)$ & 0 & 0.51 \\
\hline Gram positive bacteria & $22(4)$ & $17(5.2)$ & $5(2.2)$ & 0.085 \\
\hline Enterococcus spp. ${ }^{\mathrm{g}}$ & $16(2.9)$ & $12(3.6)$ & $4(1.8)$ & 0.20 \\
\hline Staphylococcus spp. ${ }^{\text {h }}$ & $6(1.1)$ & $5(1.5)$ & $1(0.4)$ & 0.41 \\
\hline Candida spp.' & $3(0.5)$ & $3(0.9)$ & 0 & 0.27 \\
\hline
\end{tabular}

Abbreviations: ESBL extended-spectrum beta-lactamase

${ }^{\mathrm{a}}$ Data presented as number of patients (percentages). ${ }^{\mathrm{b}}$ Include 32 (91.4\%) ESBL and 3 (8.6\%) AmpC producing strains. ${ }^{\mathrm{C}}$ Include 47 (84\%) $\mathrm{K}$. pneumoniae and 9



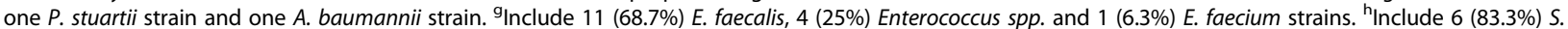
aureus and 1 (16.7\%) S. capitis strain. Include 2 C. albicans and 1 C. tropicalis strains

use were independently associated to FUTI caused by MDRO. Residing in an LTCF has been identified as a risk factor for infection caused by ESBL-producing Enterobacteria [8, 28, 29]. Pulcini et al. showed that older people from nursing homes had a $40 \%$ risk of having an antibiotic-resistant Enterobacteriaceae isolated from the urine compared to their community peers [30]. More recently, McKinnell et al. estimated a prevalence of MDRO colonization in older people from nursing homes and long-term acute care facilities of 65 and $80 \%$ respectively [31]. All these studies support the role of LTCF as reservoirs of MDRO.

Recent exposure to antimicrobials, as in previous studies, was also associated with FUTI due to MDRO $[8,28]$. Antimicrobial consumption is particularly high among residents of LTCF. It has been estimated that $75 \%$ of the residents of LTCF who stay for 6 months or longer will receive at least one course of antibiotics, commonly for suspected UTI in older patients with pyuria or ASB and non-specific urinary symptoms [18]. Given the burden of inappropriate management of ASB, particularly in LTCF, it is crucial to establish antimicrobial stewardship programs that have demonstrated to decrease antimicrobial consumption [32].

In an attempt to decrease antimicrobial overtreatment it has been recommended to avoid therapy in older patients with ASB and non-specific urinary symptoms or even to defer it in case of mild urinary symptoms awaiting urine culture results [3]. These recommendations have been questioned in an article by Gharbi et al. in which the authors suggest that not prescribing or deferring antimicrobials in older patients with a UTI 
Table 3 Univariate and multivariate analysis of risk factors associated with febrile urinary tract infection caused by multidrugresistant organisms

\begin{tabular}{|c|c|c|c|c|c|}
\hline Characteristics $^{a}$ & MDRO infection $(n=135)$ & Non-MDRO infection $(n=414)$ & $P$ value $^{2}$ & OR $(95 \% \mathrm{Cl})$ & $P$ value $^{3}$ \\
\hline Older males & $98(72.6)$ & $228(55.1)$ & $<0.001$ & & \\
\hline Previous hospital admission & $46(34.1)$ & $81(19.6)$ & 0.001 & & \\
\hline Long term care facility & $23(17)$ & $22(5.3)$ & $<0.001$ & $2.4(1.06-5.9)$ & 0.037 \\
\hline IV home-day hospital treatment & $1(0.7)$ & $12(2.9)$ & 0.2 & & \\
\hline Specialized nursing care & $2(1.5)$ & $5(1.2)$ & 0.68 & & \\
\hline Indwelling urethral catheter & $29(21.5)$ & $46(11.1)$ & 0.002 & & \\
\hline Long-term IUC & $21(15.6)$ & $19(4.6)$ & $<0.001$ & & \\
\hline Short-term IUC & $8(5.9)$ & $27(6.5)$ & 0.8 & & \\
\hline Invasive urinary Instrumentation & $38(28.1)$ & $69(16.7)$ & 0.003 & & \\
\hline Dementia & $27(20)$ & $36(8.7)$ & $<0.001$ & & \\
\hline Diabetes mellitus & $40(29.6)$ & $106(25.6)$ & 0.36 & & \\
\hline Chronic kidney failure & $16(11.9)$ & $37(8.9)$ & 0.32 & & \\
\hline Cirrhosis & $2(1.5)$ & $7(1.7)$ & 1 & & \\
\hline Neoplasia & $22(16.3)$ & $57(13.8)$ & 0.46 & & \\
\hline Heart failure & $4(3)$ & $4(1)$ & 0.1 & & \\
\hline Chronic obstructive lung disease & $30(22.2)$ & $70(16.9)$ & 0.16 & & \\
\hline Immunosuppressive or corticosteroid treatment & $1(0.7)$ & $10(2.4)$ & 0.31 & & \\
\hline Previous UTI & $74(62.2)$ & $148(40.1)$ & $<0.001$ & & \\
\hline Urinary tract abnormality & $100(74.6)$ & $236(57)$ & $<0.001$ & $2.2(1.2-3.8)$ & 0.006 \\
\hline Previous antibiotic treatment & $71(53)$ & $107(26)$ & $<0.001$ & $3.2(1.9-5.4)$ & $<0.001$ \\
\hline
\end{tabular}

Abbreviations: CI Confidence interval, IUC Indwelling urinary catheter, MDRO Multidrug-resistant organisms, OR Odds ratio, UTI Urinary tract infections

${ }^{\mathrm{a}}$ Data presented as numbers of patients (percentages). ${ }^{2}$ Univariate analysis. ${ }^{3}$ Multivariate analysis

increases the risk of bloodstream infection, hospital admission and all-cause mortality [33].

Older males with underlying urinary tract abnormalities also had an increased risk of infection by MDRO. Although having urinary abnormalities has been considered a risk factor for having UTI caused by resistant uropathogens [34] different studies show conflicting results. While Lee et al. observed a relationship between bacteremic UTI caused by MDRO and different urinary tract abnormalities [35], in a study by Gomila et al. only the presence of an IUC was associated with UTI caused by MDRO in hospitalised patients [28].

Once a FUTI is diagnosed, an empirical antimicrobial treatment has to be started to avoid progression to sepsis or even septic shock. In our study, older males received more frequently a carbapenem or piperacillin-tazobactam than non-older male. The decision to indicate a broad spectrum antibiotic should be based on the severity of the infection, the presence of known risk factors for MDRO and the local antimicrobial resistance rates. An increase in the consumption of carbapenems has been identified as a driver for carbapenemase resistance among Enterobacteriaceae strains [36]. In the present study, $21 \%$ of the older males received an IAET, which was lower than the frequency described in previous studies in older patients with UTI with rates that ranged from 27.4 to $29.3 \%$ $[26,37,38]$.

Regarding directed antimicrobial therapy, as prostatic involvement in males with FUTI is common, FQ have been considered the first therapeutic choice due to their high degree of prostatic penetration [11]. The use of FQ is limited due to high resistant rates and the risk of severe adverse events related to its use, including aortic aneurysms [39]. Co-trimoxazol is an alternative but again high resistance rates and the risk of acute kidney injury and hyperkalemia in older adults hampers its use [40]. Fosfomycine has emerged as an additional option for directed therapy as it achieves reasonable intraprostatic concentrations and it is active against most MDRO including ESBL strains [41]. Regarding the duration of antimicrobial treatment in males with FUTI, very few studies have analysed this topic. Ulleryd et al. showed that 14 day was not inferior to 28 day treatment while more recently van Niewkoop et al. demonstrated that 7 days was less efective than 14 day treatment in males with FUTI [42, 43]. In our study, older and non-older patients received slightly more than 2 weeks of antimicrobial therapy.

Management of IUC in FUTI is also important, particularly in older patients who are frequently catheterized. 
IDSA guidelines recommend replacing a long-term IUC to hasten the resolution of symptoms in catheterassociated UTI [44]. This recommendation has recently been questioned in a study by Babich et al. in which the authors found no clinical benefit from replacing a longterm IUC at the onset of a catheter-associated UTI [45]. In a later editorial letter, the authors were questioned about the IDSA guidance to obtain a urine culture from a freshly placed catheter as a sample from a long-term IUC might not reflect the status of the infection in the bladder. The authors replied that in $97 \%$ of cases of bacteremia the same species was isolated from the urine while recognizing the need for further research with randomized controlled trials [46].

As in previous studies, older patients required hospital admission more frequently with longer length of hospitalization $[3,12]$. Also, older patients had an inhospital mortality rate of $4.3 \%$, which was higher compared to non-older patients but significantly lower than the rates reported in previous studies in geriatric patients with UTI with rates that ranged from 8.9 to $33 \%$ $[26,37,47,48]$. Severe sepsis and septic shock are the risk factors that most robustly have been associated with increased mortality in patients with FUTI [26, 38, 47]. Despite several studies have found age to increase mortality in patients with sepsis $[26,38,47]$, others point out that preexisting medical conditions, including chronic kidney failure, could play a more prominent role $[49,50]$.

The present study has some potential limitations that have to be taken into consideration. Firstly, the study had a retrospective component and was performed in a single hospital. Secondly, we did not evaluate certain clinical data that would have been worth analysing in older male patients with FUTI including the functional status, the presence of urinary incontinence, altered mental status or delirium. Thirdly, we excluded from the analysis FUTI episodes with negative or polymicrobial urine culture which might have induced a selection bias. Finally, the data collection was limited to the hospitalization period which might have underestimated the outcomes.

\section{Conclusions}

Despite these limitations, our study indicates that older males with FUTI present different clinical characteristics and show specific microbiological features and increased antimicrobial resistance rates. In the multivariate analysis age was not associated with infections caused by MDRO.

\footnotetext{
Abbreviations

ABP: Acute bacterial prostatitis; ASB: Asymptomatic bacteriuria; BPH: Benign prostatic hyperplasia; ED: Emergency department; ESBL: Extended-spectrum betalactamase; FQ: Fluoroquinolones; FUTI: Febrile urinary tract infections; HCA: Healthcare-associated; IEAT: Inadequate empirical antimicrobial treatment; IUC: Indwelling urinary catheter; LTCF: Long-term care facility; LUTS: lower urinary tract symptoms; MAP: Mean arterial pressure;
}

MDRO: Multidrug-resistant organisms; OPAT: Outpatient parenteral antimicrobial treatment; TGC: Third-generation cephalosporins; UTI: Urinary tract infections

\section{Acknowledgements}

Not applicable.

\section{Authors' contributions}

AS contributed to the study design, data collection, analysis, interpretation of the results and wrote the article. JR, EN, AC, UP, MF and MTB were involved in the analysis and interpretation of the results and made a critical revision of the manuscript. All the authors read and approved the submitted manuscript.

\section{Funding}

The study was performed without specific funding.

\section{Availability of data and materials}

The datasets used and/or analysed during the current study are available from the corresponding author on reasonable request.

\section{Ethics approval and consent to participate}

The study was approved by the Ethics Committee of the "La Fundació Unió Catalana d'Hospitals (CEIC 16/58)". Written informed consent was obtained

from all patients prospectively included.

\section{Consent for publication}

Not applicable.

\section{Competing interests}

Dr. Alex Smithson is a member of the editorial board (Associate Editor) of BMC Geriatrics. Despite forming part of the editorial board, he had no role in the editorial process of this manuscript. Dr. Javier Ramos, Dr. Esther Niño, Dr. Alex Culla, Dr. Ubaldo Pertierra, Dr. Michele Friscia and Dr. Maria Teresa

Bastida have no conflicts of interest to disclose.

\section{Author details}

${ }^{1}$ Infectious Diseases Unit, Fundació Hospital de I'Esperit Sant, C/Avinguda Mossen Pons i Rabadà s/n, 08923 Santa Coloma Gramenet, Spain. ${ }^{2}$ Internal Medicine Department, Fundació Hospital de l'Esperit Sant, C/Avinguda Mossen Pons i Rabadà s/n, 08923 Santa Coloma Gramenet, Spain. ${ }^{3}$ Microbiology Laboratory, Fundació Hospital de I'Esperit Sant, C/Avinguda Mossen Pons i Rabadà s/n, 08923 Santa Coloma Gramenet, Spain.

Received: 16 April 2019 Accepted: 19 November 2019

Published online: 29 November 2019

\section{References}

1. Available at: https:/ec.europa.eu/info/sites/info/files/economy-finance/ ip065_en.pdf. Accessed Feb 2019.

2. Rowe TA, McKoy JM. Sepsis in older patients. Infect Dis Clin N Am. 2017;31: 731-42.

3. Nicolle LE. Urinary tract infections in the older adult. Clin Geriatr Med. 2016; 32:523-38.

4. Yahav D, Eliakim-Raz N, Leibovici L, Paul M. Bloodstream infection in older patients. Virulence. 2016;7:341-52.

5. Curns AT, Holman RC, Sejvar JJ, Owings MF, Schonberger LB. Infectious disease hospitalizations among older adults in the United States from 1990 to 2002. Arch Inter Med. 2005:165:2514-20.

6. Sundvall PD, Elm M, Ulleryd P, Mölstad S, Rodhe N, Jonsson L, et al. Interleukin-6 concentrations in the urine and dipstick analyses were related to bacteriuria but not symptoms in the elderly: a cross sectional study of 421 nursing home residents. BMC Geriatr. 2014. https://doi.org/10.1186/ 1471-2318-14-88.

7. Sundvall PD, Stuart B, Davis M, Roderick P, Moore M. Antibiotic use in the care home setting: a retrospective cohort study analysing routine data. BMC Geriatr. 2015. https://doi.org/10.1186/s12877-015-0073-5.

8. Ben-Ami R, Rodríguez-Baño J, Arslan H, Pitout JD, Quentin C, Calbo ES, et al. A multinational survey of risk factors for infection with extended-spectrum beta-lactamase-producing enterobacteriaceae in nonhospitalized patients. Clin Infect Dis. 2009:49:682-90. 
9. Schaeffer AJ, Nicolle LE. Urinary tract infections in older men. N Engl J Med. 2016;374:562-71.

10. Ulleryd P, Zackrisson B, Aus G, Bergdahl S, Hugosson J, Sandberg T. Prostatic involvement in men with febrile urinary tract infection as measured by serum prostate-specific antigen and transrectal ultrasonography. BJU Int. 1999:84:470-4.

11. Lipsky BA, Byren I, Hoey CT. Treatment of bacterial prostatitis. Clin Infect Dis. 2010;50:1641-52.

12. Chang UI, Kim HW, Noh YS, Wie SH. A comparison of the clinical characteristics of elderly and non-elderly women with communityonset, non-obstructive acute pyelonephritis. Korean J Intern Med. 2015; 30:372-83.

13. Wie SH, Kim HW, Chang UI. Effects of gentamicin monotherapy for the initial treatment of community-onset complicated non-obstructive acute pyelonephritis due to Enterobacteriaceae in elderly and non-elderly women. Clin Microbiol Infect. 2014;20:1211-8.

14. Charlson ME, Pompei P, Ales KL, MacKenzie CR. A new method of classifying prognostic comorbidity in longitudinal studies: development and validation. J Chronic Dis. 1987:40:373-83.

15. Magiorakos AP, Srinivasan A, Carey RB, Carmeli Y, Falagas ME, Giske CG, et al. Multidrug-resistant, extensively drug-resistant and pandrug-resistant bacteria: an international expert proposal for interim standard definitions for acquired resistance. Clin Microbiol Infect. 2012;18:268-81.

16. Levy MM, Fink MP, Marshall JC, Abraham E, Angus D, Cook D, et al. SCCM/ ESICM/ACCEP/ATS/SIS international Sepsis definitions conference. Crit Care Med. 2003;31:1250-6.

17. Nicolle LE. Urinary tract pathogens in complicated infection and in elderly individuals. J Infect Dis. 2001;183(Suppl 1):S5-8.

18. Jump RLP, Crnich CJ, Mody L, Bradley SF, Nicolle LE, Yoshikawa TT. Infectious diseases in older adults of long-term care facilities: update on approach to diagnosis and management. J Am Geriatr Soc. 2018;66:789803.

19. Søgaard KK, Veres K, Nørgaard M, Djurhuus JC, Sørensen HT. Pyelonephritis in persons after age 50 as a clinical marker of urogenital cancer. Clin Microbiol Infect. 2019;25:87-91.

20. Caterino JM, Ting SA, Sisbarro SG, Espinola JA, Camargo CA Jr. Age, nursing residence, and presentation of urinary tract infection in US emergency department, 2001-2008. Acad Emerg Med. 2012;19:1173-80.

21. Norman DC. Clinical features of infection in older adults. Clin Geriatr Med. 2016;32:433-41.

22. Magny E, Le Petitcorps H, Pociumban M, Bouksani-Kacher Z, Pautas É, Belmin J, et al. Predisposing and precipitating factors for delirium in community-dwelling older adults admitted to hospital with this condition: a prospective case series. PLoS One. 2018. https://doi.org/10.1371/journal. pone.0193034.

23. Balogun SA, Philbrick JT. Delirium, a symptom of UTI in the elderly: fact or fable? A Systematic Review. Can Geriatr J. 2013;17:22-6.

24. van Buul LW, Vreeken HL, Bradley SF, Crnich CJ, Drinka PJ, Geerlings SE, et al. The development of a decision tool for the empiric treatment of suspected urinary tract infection in frail older adults: a Delphi consensus procedure. J Am Med Dir Assoc. 2018;19:757-64.

25. Nicolle LE, Gupta K, Bradley SF, Colgan R, DeMuri GP, Drekonja D, et al. Clinical practice guideline for the Management of Asymptomatic Bacteriuria: 2019 update by the Infectious Diseases Society of America. Clin Infect Dis. 2019. https://doi.org/10.1093/cid/ciy1121.

26. Álvarez Artero E, Campo Nuñez A, Garcia Bravo M, Cores Calvo O, Belhassen Garcia M, Pardo Lledias J, en nombre del Grupo colaborativo de estudio de infecciones urinarias en el anciano. Urinary infection in the elderly. Rev Clin Esp. 2019. https://doi.org/10.1016/j.rce.2018.10.009.

27. Lee DS, Choe HS, Kim HY, Yoo JM, Bae WJ, Cho YH, et al. Role of age and sex in determining antibiotic resistance in febrile urinary tract infections. Int J Infect Dis. 2016;51:89-96.

28. Gomila A, Shaw E, Carratalà J, Leibovici L, Tebé C, Wiegand I, et al. Predictive factors for multidrug-resistant gram-negative bacteria among hospitalised patients with complicated urinary tract infections. Antimicrob Resist Infect Control. 2018. https://doi.org/10.1186/s13756-018-0401-6.

29. Briongos-Figuero LS, Gómez-Traveso T, Bachiller-Luque P, Domínguez-Gil González M, Gómez-Nieto A, Palacios-Martín T, et al. Epidemiology, risk factors and comorbidity for urinary tract infections caused by extendedspectrum beta-lactamase (ESBL)-producing enterobacteria. Int I Clin Pract. 2012;66:891-6.
30. Pulcini C, Clerc-Urmes I, Attinsounon CA, Fougnot S, Thilly N. Antibiotic resistance of Enterobacteriaceae causing urinary tract infections in elderly patients living in the community and in the nursing home: a retrospective observational study. J Antimicrob Chemother. 2019;74:775-81.

31. McKinnell JA, Singh RD, Miller LG, Kleinman K, Gussin G, He J, et al. The SHIELD Orange County project -multi drug-resistant organism (MDRO) prevalence in 21 nursing homes and long term acute care facilities in Southern California. Clin Infect Dis. 2019. https://doi.org/10.1093/cid/ciz119.

32. Flokas ME, Andreatos $\mathrm{N}$, Alevizakos M, Kalbasi A, Onur P, Mylonakis E. Inappropriate Management of Asymptomatic Patients with Positive Urine Cultures: a systematic review and meta-analysis. Open Forum Infect Dis. 2017. https://doi.org/10.1093/ofid/ofx207.

33. Gharbi M, Drysdale JH, Lishman H, Gharbi M, Drysdale JH, Lishman H, et al. Antibiotic management of urinary tract infection in elderly patients in primary care and its association with bloodstream infections and all cause mortality: population based cohort study. BMJ. 2019. https://doi.org/10. 1136/bmj.1525.

34. Beahm NP, Nicolle LE, Bursey A, Smyth DJ, Tsuyuki RT. The assessment and management of urinary tract infections in adults: guidelines for pharmacists. Can Pharm J. 2017;150:298-305.

35. Lee YC, Hsiao CY, Hung MC, Hung SC, Wang HP, Huang YJ, Wang JT. Bacteremic urinary tract infection caused by multidrug- resistant Enterobacteriaceae are associated with severe sepsis at admission: implication for empirical therapy. Medicine (Baltimore). 2016. https://doi.org/ 10.1097/MD.00000000000003694.

36. McLaughlin M, Advincula MR, Malczynski M, Qi C, Bolon M, Scheetz MH. Correlations of antibiotic use and carbapenem resistance in enterobacteriaceae. Antimicrob Agents Chemother. 2013;57:5131-3.

37. Esparcia A, Artero A, Eiros JM, Balaguer M, Madrazo M, Alberola J, et al. Influence of inadequate antimicrobial therapy on prognosis in elderly patients with severe urinary tract infections. Eur J Intern Med. 2014;25:523-7.

38. Artero A, Inglada L, Gómez-Belda A, Capdevila JA, Diez LF, Arca A, et al. The clinical impact of bacteremia on outcomes in elderly patients with pyelonephritis or urinary sepsis: a prospective multicenter study. PLoS One. 2018. https://doi.org/10.1371/journal.pone.0191066.

39. Pasternak B, Inghammar M, Svanström H. Fluoroquinolone use and risk of aortic aneurysm and dissection: nationwide cohort study. BMJ. 2018. https:// doi.org/10.1136/bmj.k678.

40. Crellin E, Mansfield KE, Leyrat C, Nitsch D, Douglas IJ, Root A, et al. Trimethoprim use for urinary tract infection and risk of adverse outcomes in older patients: cohort study. BMJ. 2018. https://doi.org/10.1136/bmj.k341

41. Zhanel GG, Zhanel MA, Karlowsky JA. Oral fosfomycin for the treatment of acute and chronic bacterial prostatitis caused by multidrug-resistant Escherichia coli. Can J Infect Dis Med Microbiol. 2018. https://doi.org/10. 1155/2018/1404813

42. Ulleryd P, Sandberg T. Ciprofloxacin for 2 or 4 weeks in the treatment of febrile urinary tract infection in men: a randomized trial with a 1 year follow-up. Scand J Infect Dis. 2003;35:34-9.

43. van Nieuwkoop C, van der Starre WE, Stalenhoef JE, van Aartrijk AM, van der Reijden TJ, Vollaard AM, et al. Treatment duration of febrile urinary tract infection: a pragmatic randomized, double-blind, placebo-controlled noninferiority trial in men and women. BMC Med. 2017. https://doi.org/10.1186/ s12916-017-0835.

44. Hooton TM, Bradley SF, Cardenas DD, Colgan R, Geerlings SE, Rice JC. Diagnosis, prevention, and treatment of catheter-associated urinary tract infection in adults: 2009 international clinical practice guidelines from the Infectious Diseases Society of America. Clin Infect Dis. 2010;50:62563.

45. Babich T, Zusman O, Elbaz M, Ben-Zui H, Paul M, Leibovici L, et al. Replacement of urinary catheter for uninary tract infections: a prospective observation study. J Am Geriatr Soc. 2018;66:1779-84.

46. Babich T, Leibovici L, Avni T. Reply to : replacing urine catheters for urinary tract infections: a closer look. J Am Geriatr Soc. 2019;67:621-2.

47. Eliakim-Raz N, Babitch T, Shaw E, Addy I, Wiegand I, Vank C, et al. Risk factors for treatment failure and mortality among hospitalized patients with complicated urinary tract infection: a multicenter retrospective cohort study (RESCUING study group). Clin Infect Dis. 2019;68:29-36.

48. Tal S, Guller V, Levi S, Bardenstein R, Berger D, Gurevich I, et al. Profile and prognosis of febrile elderly patients with bacteremic urinary tract infection. J Inf Secur. 2005;50:296-305. 
49. Rhee C, Jones TM, Hamad Y, Pande A, Varon J, O'Brien C, et al. Prevalence, underlying causes, and preventability of sepsis-associated mortality in US acute care hospitals. JAMA Netw Open. 2019. https://doi.org/10.1001/ jamanetworkopen.2018.7571.

50. Mansur A, Mulwande E, Steinau M, Bergmann I, Popov AF, Ghadimi M, Beissbarth T, Bauer M, Hinz J. Chronic kidney disease is associated with a higher 90-day mortality than other chronic medical conditions in patients with sepsis. Sci Rep. 2015. https://doi.org/10.1038/srep10539.

\section{Publisher's Note}

Springer Nature remains neutral with regard to jurisdictional claims in published maps and institutional affiliations.

Ready to submit your research? Choose BMC and benefit from:

- fast, convenient online submission

- thorough peer review by experienced researchers in your field

- rapid publication on acceptance

- support for research data, including large and complex data types

- gold Open Access which fosters wider collaboration and increased citations

- maximum visibility for your research: over $100 \mathrm{M}$ website views per year

At $\mathrm{BMC}$, research is always in progress.

Learn more biomedcentral.com/submissions 